\title{
The battery of silos for rapeseed - the impact of the building quality and exploitation conditions on the technical state of the object
}

\author{
Krystyna Wróbel*, and Wiestaw Kubiszyn \\ Faculty of Civil and Environmental Engineering and Architecture, Rzeszow University of \\ Technology, Al. Powstańców Warszawy 12, 35-959 Rzeszow, Poland,
}

\begin{abstract}
The subject of the paper is a battery of silos for rapeseed located in Oil Factory in Bodaczów. It consists of 24 cylindrical silos with capacity of 500 tons and 14 star-shaped chambers between them with a capacity of 100 tons each. The silos were supported on the supporting structure in the form of permeating ring beams and columns. The height of a single silo is $25 \mathrm{~m}$, and the diameter about $6.0 \mathrm{~m}$. Detailed macroscopic tests were performed on the battery of silos. Destructive and sclerometric in-situ quality tests and pull-off test were performed on the concrete, the degree of concrete carbonation was estimated. The position of the reinforcement in the concrete structure and the corrosion of the reinforcement steel were determined. Static and strength calculations were carried out. Based on the results the technical condition of the object was estimated as poor, locally due to the significant loss of concrete and structural reinforcement it was estimated as imminent failure. The article presents the results of these tests, describes the reasons for the poor technical condition of the structure and presents solutions to restore its functional efficiency. A comprehensive repair of the battery of silos is currently underway applying the proposed solutions.
\end{abstract}

\section{Introduction}

In the 60 's and 70's of the last century, a large number of different types of reinforced concrete silos were built to store loose materials. These objects are still very often in use. Most of them are exploited until technical wear without major repairs and the owners maintenance. Due to the problems associated with their technical condition, they are the subject of many expert opinions and scientific publications. The country hosts regular conferences devoted to the issues of safety and maintenance of industrial facilities, including silos. Examples are the following conferences: "Awarie Budowlane" (Construction failures) [1, 2], "Budownictwo w energetyce" (Construction in the energy sector) [3]. The subject of the article is a battery of rapeseed silos in Oil Factory in Bodaczów near Zamość, which has been in operation since the 1960s. The object was built in sliding technology. It changed the owner in 2011 and was subjected to a detailed

* Corresponding author: wrobel@prz.edu.pl 
diagnosis in 2017 [4]. Currently it is being renovated based on this diagnosis. Figures 1 and 2 show the scheme and a cross-section of a silos battery together with an operating tower.

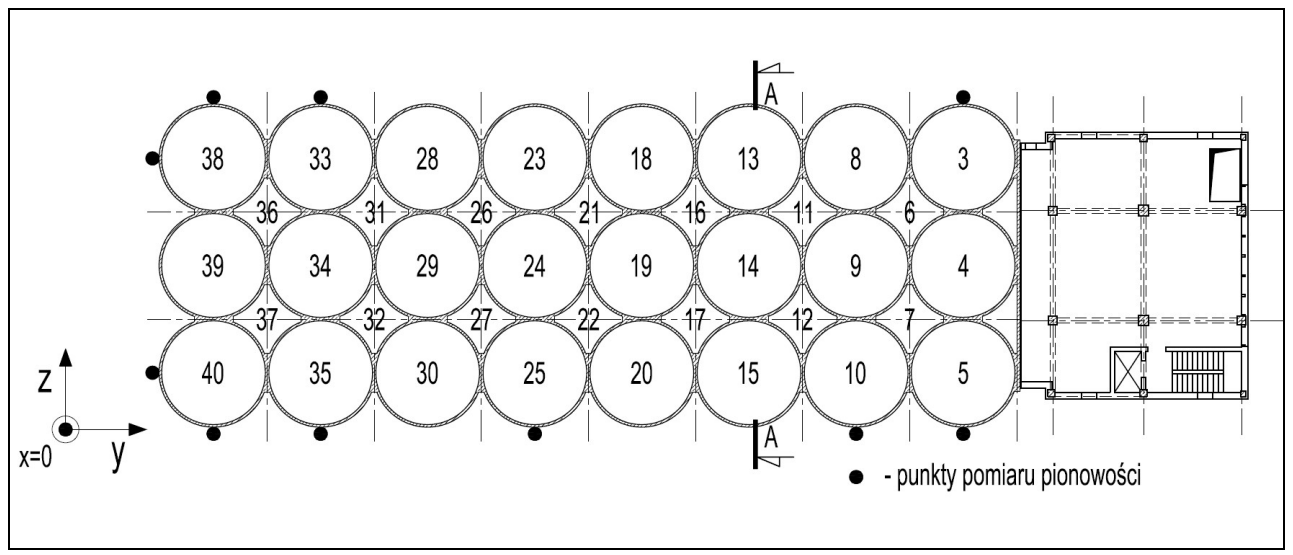

Fig. 1. Scheme of silos battery with an operating tower

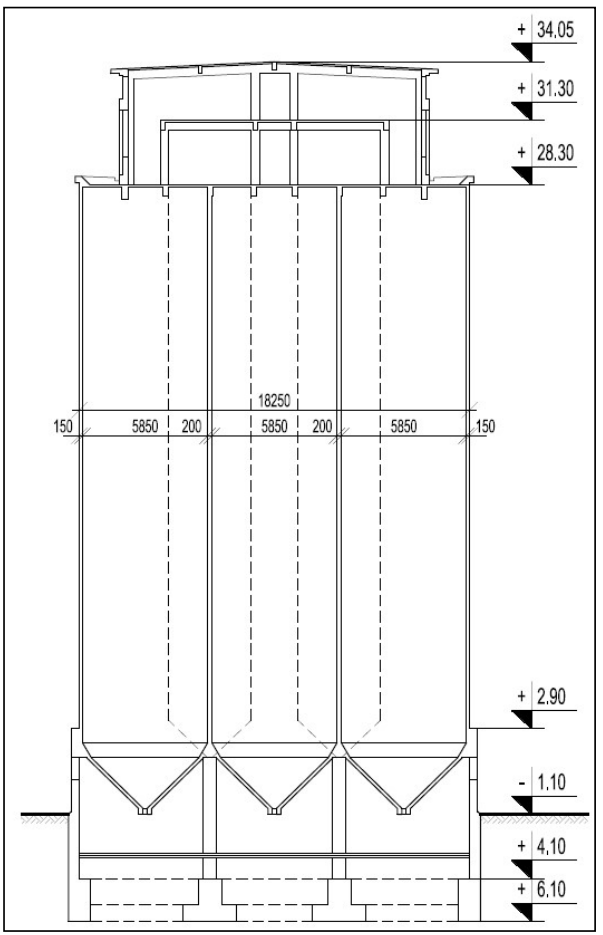

Fig. 2. Cross-section A-A of silos battery

\section{Description of the object}

The silos battery consists of 24 cylindrical silos with a capacity of 500 tons each and 14 star-shaped chambers, with a capacity of 100 tons each. The height of a single silo is $25 \mathrm{~m}$ and the diameter about $6.0 \mathrm{~m}$. The silos were supported on the supporting structure in the form of permeating ring beams and columns. In each silo, a reinforced concrete conical 
hoppers are attached to these ring beams. The columns were placed on a reinforced concrete foundation grate $2.0 \mathrm{~m}$ high, at a depth of $5.0 \mathrm{~m}$ below the ground level. Each silo is covered with a reinforced concrete slab-beam floor. A longitudinal two-storey grain transport gallery was located on the silo floor. The shape and location of the gallery are shown in the figure No 2. Partially, the floor slab protrudes from the outline of the transport gallery. The roofing is made of bituminous felt. Enclosure of the silo support structure at the ground floor level and storey "-1" level is made of silicate bricks.

\section{Description of damage}

The walls from the outside - a general view of the silos battery is shown in Fig. 3. The damage was determined on the basis of detailed macroscopic examinations and revision holes. The detailed macroscopic tests were carried out for silos No. 5, 8, 10, 15, 25, 38-40. These test were made from the external staircase, climbing and climbing scaffolding. Throughout the external surface of the silos, circumferential damage was found every 0.3 to $0.7 \mathrm{~m}$ along the height of the silos, resulting from improper lifting of formwork during concreting (Fig. 4). In the areas of leaks, the structure of the concrete has been disturbed and additionally weakened due to the long-term impact of adverse weather conditions. The range of losses and loosening of the concrete lagging of horizontal and vertical reinforcement bars has significantly increased. Founded advanced corrosion of reinforcement bars.

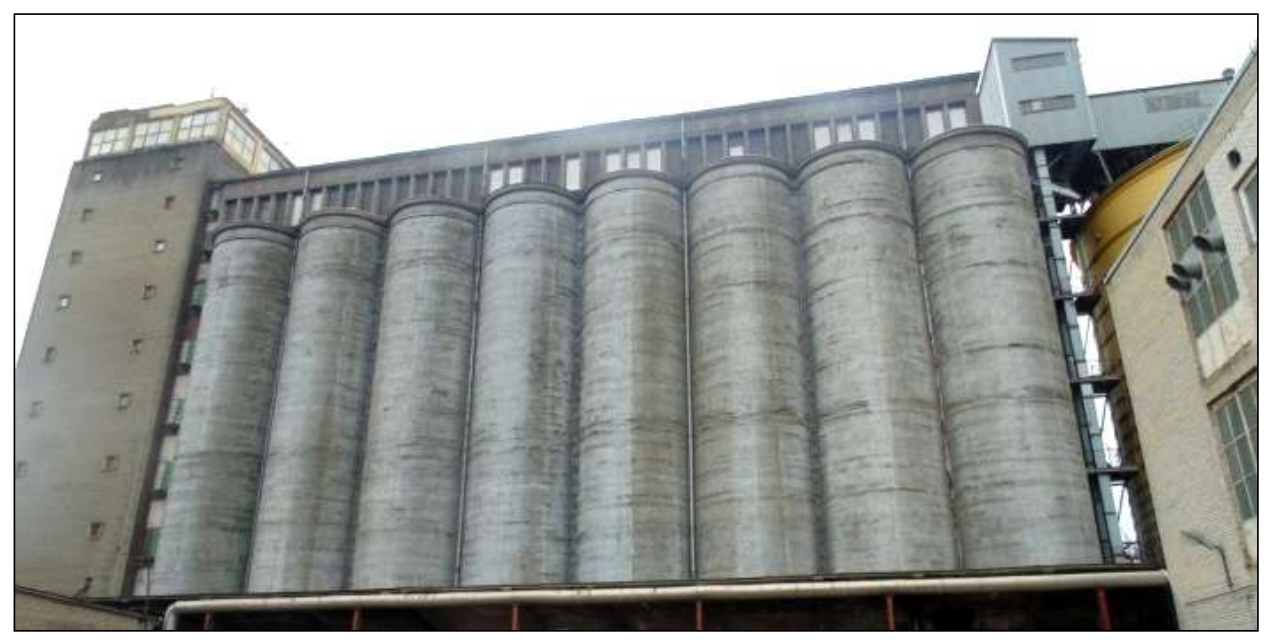

Fig. 3. General view of the silos battery from the north side

Corrosion products of the reinforcement damaged the concrete (Fig. 4-9). In the areas of the above mentioned damage there is no adhesion of concrete and reinforcement bars. Concrete structural defects were also found, consisting in segregating the concrete mix components (Fig. 9). The repair mortar falls in the areas of improper repairs of the damaged concrete structure. These repairs were made without proper substrate preparation, the weak concrete was not removed to a sufficient extent. As a result, a strong repair mortar falls off together with a layer of weak concrete (which was supposed to be repaired).

The thickness of the spontaneously falling concrete layer reaches up to around $7 \mathrm{~cm}$ in many places. Disintegrating pieces of concrete pose a threat to life and health of people and property. Corrosion damage is greatest in the lower part of the silos, over the supporting ring coat (Fig. 8, 9) - there is extensive surface corrosion of concrete, poor quality or 
carbonated concrete. Non-concretes and segregation of concrete components during concreting were found. River aggregate contaminated with clay was locally used for the construction of silos. Cereal moths and other vermins were observed nested in the wall of one of the silos.

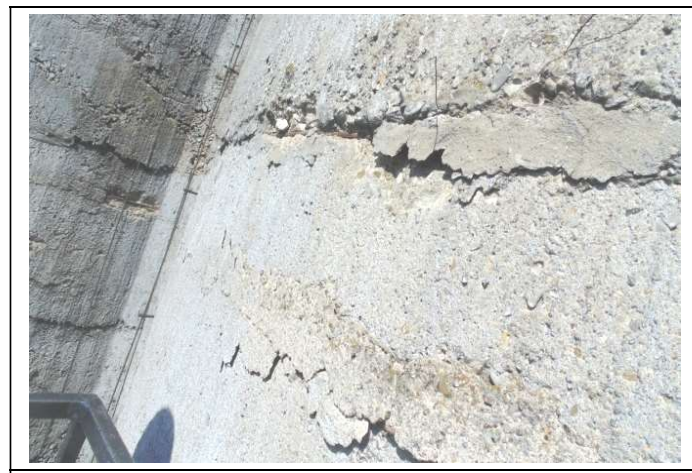

Fig. 4. Separation of concrete cover at the level of working gaps

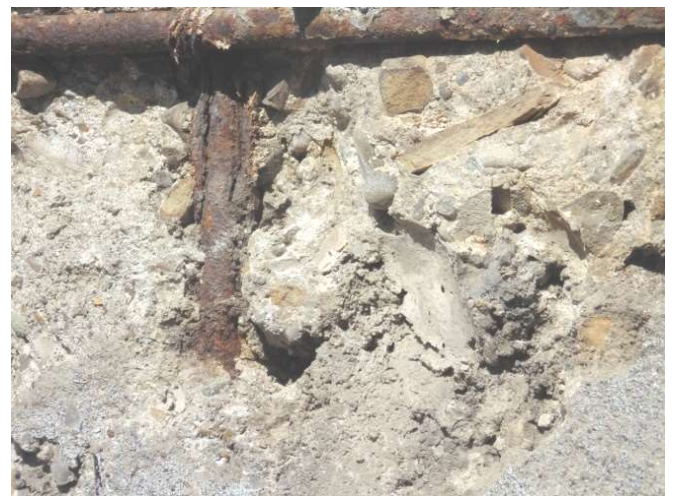

Fig. 6. Advanced surface corrosion of vertical reinforcement

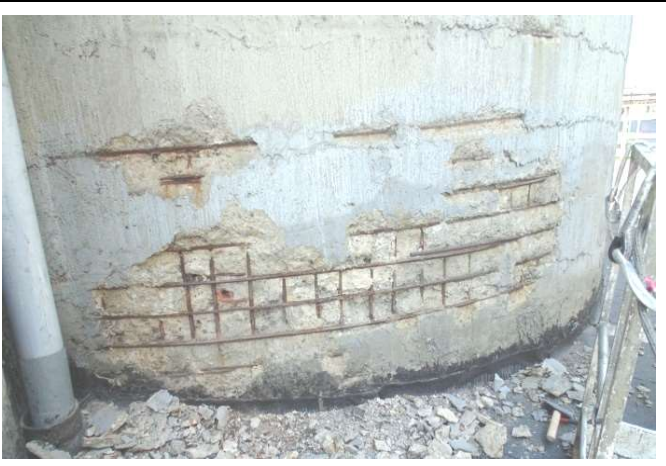

Fig. 8. Extensive surface corrosion of concrete, large corrosion defects of reinforcement

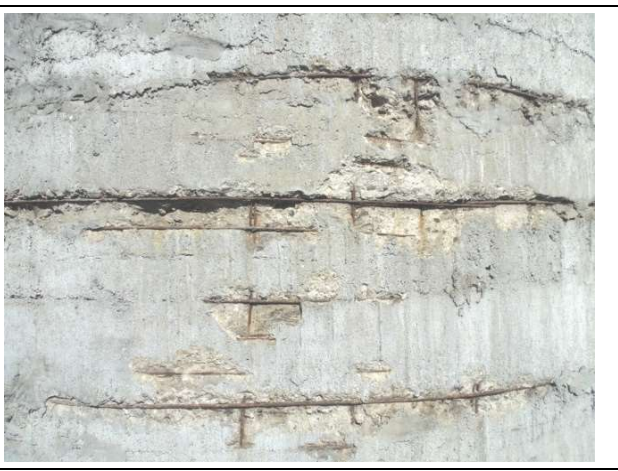

Fig. 5. Surface corrosion of concrete, locally there is a lack of reinforcement cover

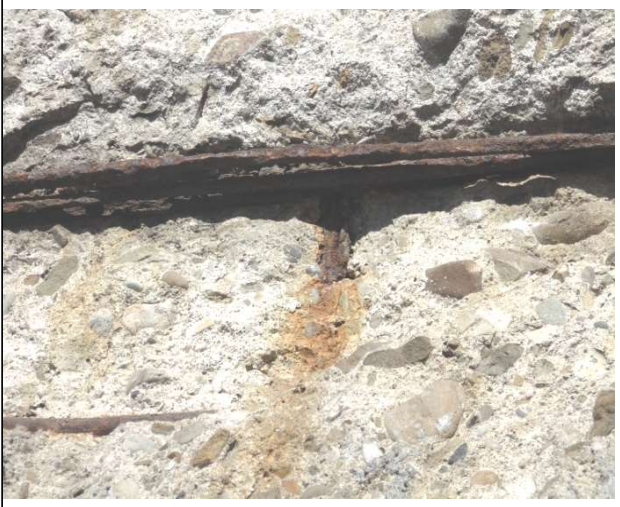

Fig. 7. Completely corroded vertical bar, advanced surface and pitting corrosion of horizontal reinforcement, no adhesion of concrete to reinforcement

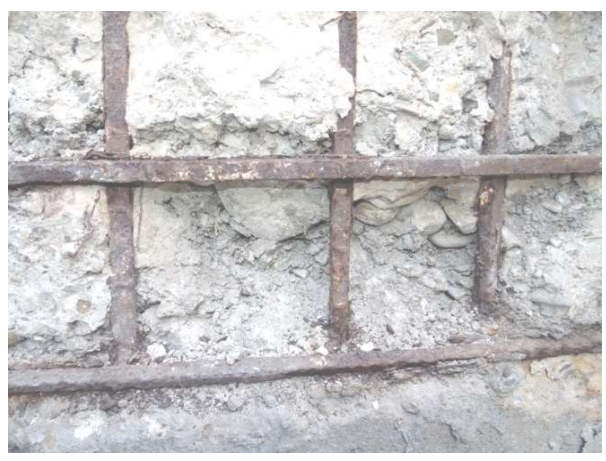

Fig. 9. Details of Fig. No. 8 
Revision of the chambers from the inside: silo No. 8 and adjacent star chamber No. 11 were revised inside. The general condition of the interior was good. Only in silo no. 8 a local leak of the external wall (also visible from the outside) was found.

Silos covering and transport gallery over silos is partially renovated and partially in poor technical condition. Flashings are locally corroded and decomposed. Locally gutters and downpipes are missing.

The cover of the part below the level of $+2.90 \mathrm{~m}$ is destroyed and technically worn. The roofing plate of the part which is beyond the outline of the silos is corroded (Fig. 10). The rainwater drainage system was made inside the building. It is leaking and incomplete. Rainwater flowing into the building caused corrosion damage to supporting structures of silos (ring beams and columns) and hoppers (Figures 10,11). Outer walls of brick are damp and moldy. There is no horizontal and vertical waterproofing.

Immediately after the heavy rain huge stains and puddles of water appeared inside the building - on both floors of the transport gallery as well as on the "-1" storey. This indicates that all safety elements (roofing, gutters and downpipes, anti-moisture insulation, dilatation seals - if they existed at all) have aged, corroded, became incomplete, leaky and deformed. They ceased to perform the technical function to which they were intended. This results in the fact that the technical condition of load-bearing, finishing and other elements degrades at an accelerated pace.

\begin{tabular}{|l|l|}
\hline & \\
\hline Fig. 10. Corrosion of the floor slab at the level of & $\begin{array}{l}\text { Fig. 11. Examples of corrosion damage of the } \\
\text { silo support structure }\end{array}$ \\
\hline$+2.90 \mathrm{~m}$ & 2017
\end{tabular}

\section{Description of the tests and performed revision holes}

\section{1) Sclerometric tests of concrete quality}

The strength test and assessment of the homogeneity of structural elements concrete were made on the basis of sclerometer measurements using the $\mathrm{N}$ type Schmidt hammer, PROCEQ - DIGISCHMIDT. The measurements were made and the results were developed according to codes $[5,6]$ and technical literature. The test results are provided in the table No 1. 
Table 1. Results of sclerometric tests of concrete walls of silos

\begin{tabular}{|c|c|c|}
\hline Silo number & $\mathrm{f}_{\mathrm{ck}, \mathrm{m}}[\mathrm{MPa}]$ & Concrete class \\
\hline 15 & 36.33 & $\mathrm{C} 30 / 37$ \\
\hline 25 & 36,29 & $\mathrm{C} 30 / 37$ \\
\hline 38 & 34,47 & $\mathrm{C} 30 / 37$ \\
\hline 39 & 34,26 & $\mathrm{C} 30 / 37$ \\
\hline 40 & 37,10 & $\mathrm{C} 30 / 37$ \\
\hline
\end{tabular}

2) Pull-off test of concrete walls of silos

One test area per the surface of the walls of silos No 38 and 39 was selected. Five samples were prepared in each field to determine the tensile strength of concrete in accordance with the standard [7]. The average values of the measurement results and the value of breaking force are given in the table No 2 .

Table 2. Results of pull-of tests of concrete walls of silos

\begin{tabular}{|c|c|c|c|}
\hline Silo number & $\mathrm{F}_{\mathrm{n}}[\mathrm{N}]$ & $\mathrm{A}\left[\mathrm{mm}^{2}\right]$ & $\mathrm{f}_{\mathrm{ctm}}\left[\mathrm{N} / \mathrm{mm}^{2}\right]$ \\
\hline 38 & 5637 & 1900 & 2,97 \\
\hline 39 & 4749 & 1900 & 2,50 \\
\hline
\end{tabular}

$\mathrm{F}_{\mathrm{n}}$ - Average breaking force,

A - Area of the sample

$\mathrm{f}_{\mathrm{ctm}}$ - Medium tensile strength of concrete

3) Measurements of distribution of reinforcement in the walls of silos and measurements of the depth of concrete carbonation

The location of the reinforcement in the external walls of the silos was determined in detail using the magnetic method using Proceq PROFEMET 5 device from the Swiss company Proceq in accordance with the manufacturer's instructions. Distances between horizontal and vertical reinforcement bars were determined. The place of revision holes were selected to directly examine the reinforcement, measure the thickness of the cover layer and determine the depth of carbonation of the concrete. The depth of neutralization (range of carbonation) in concrete was determined with a $1 \%$ solution of phenolphthalein in ethyl alcohol. This method is included in the standard [8]. The surface of the concrete was cleaned of dust and loose particles without the use of water and abrasion. Then the phenolphthalein solution was applied. The depth of the concrete neutralization was measured based on the color of the exposed surface. Below, in Fig. 12 and 13, two examples of revision holes (before and after the test) are shown, in areas outside the damages where the quality of the concrete was very good. In such areas, the depth of the concrete neutralization of $5 \div 20 \mathrm{~mm}$ was found. However, in the areas of defects and corrosion damage, the front of the carbonation went deep beyond the reinforcing bars. 


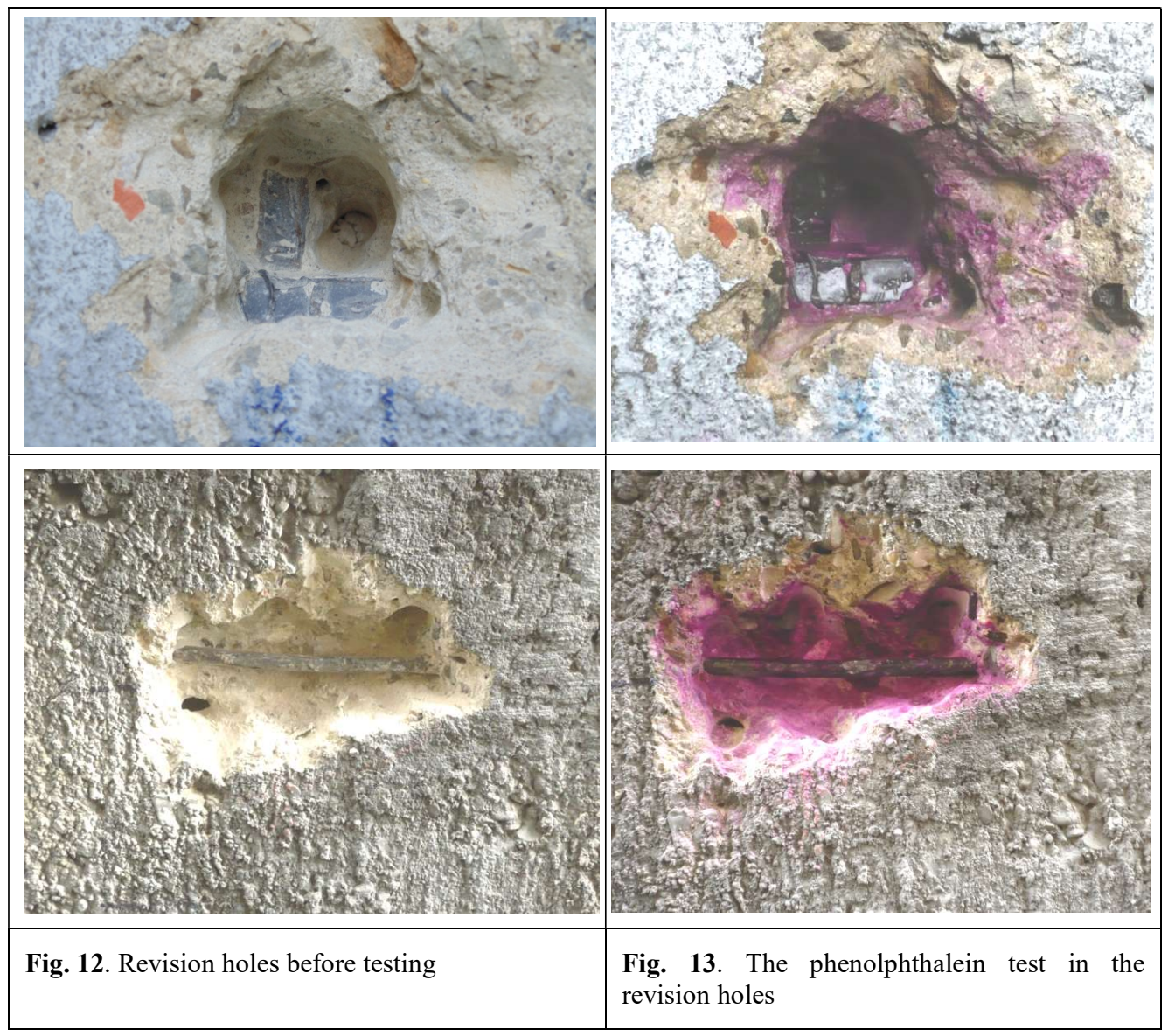

4) Laboratory tests of reinforcing steel parameters (Fig 14, 15)

Due to the significant corrosion losses of reinforcement of silos and the necessity to supplement them, laboratory tests of this steel were carried out. The tests covered the determination of the reinforcing bars yield stress (bars were cut out of the structure) and the weldability of these bars to reinforcing bars made of B500SP steel.

The real steel parameters obtained from laboratory destructive tests of reinforcing bars taken from the structure are:

- for round bars: $\mathrm{R}_{\mathrm{e}, \min }=255 \mathrm{MPa}$,

- for square bars: $\mathrm{R}_{\mathrm{e}, \min }=315 \mathrm{MPa}$.

Reinforcing bars used for the structure of the silo are weldable to steel B500SP. The breaking of all bars occurred outside the area of welds 


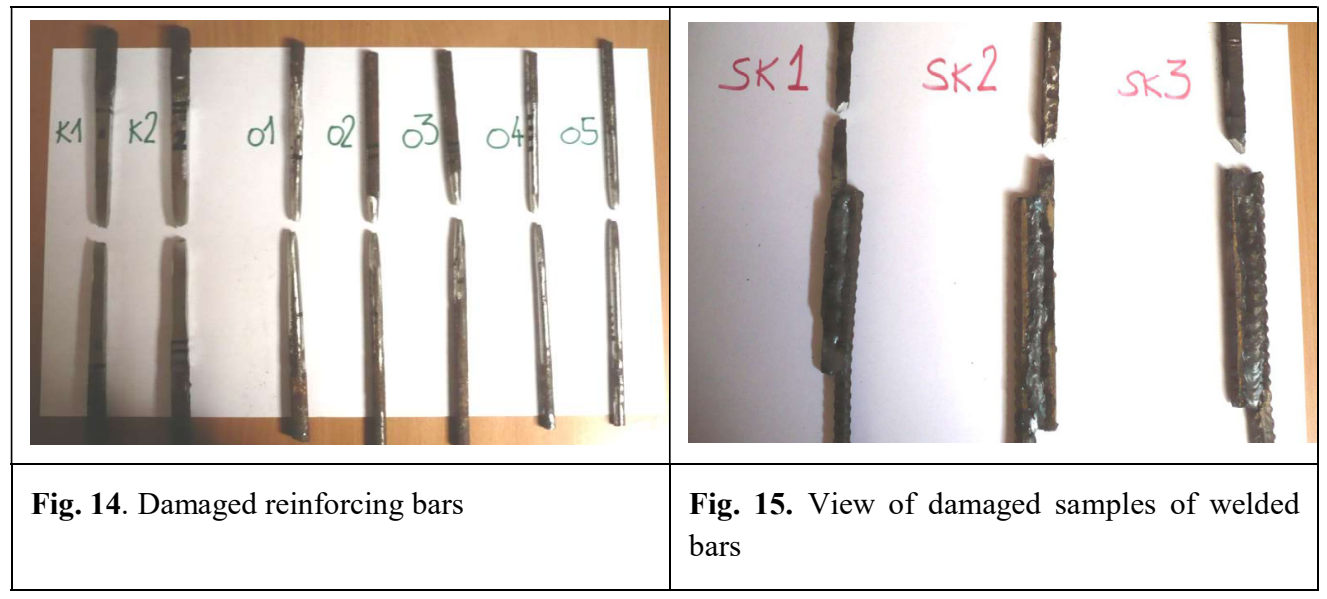

5) Geodetic measurements of verticality of silo walls

Vertical measurements were performed for selected silos (No 3, 5, 10, 25, 33, 35, 38, 40) during favorable weather conditions - lack of intense sun exposure and strong wind. The arrangement of the axes and the location of the measuring points are shown in Fig. 1. Permissible executive deviations were determined based on [9]. Allowed vertical deflection for the silos is $D_{\lim }=H / 500=51 \mathrm{~mm}$. Measured deformations only for two silos (No. 10 and 25) slightly exceed the limiting value (less than 10\%).

\section{Checking static and strength calculations}

Assumptions for calculations:

1) The calculations were performed using the limit states method on the basis of currently applicable standards, including [10, 11, 12].

2) The calculations were performed for the wall of silo in the external row, located between two silos, but not being a corner silo.

3) The calculations included:

- steel parameters assumed at the design stage,

- real steel parameters obtained from laboratory destructive tests of reinforcing bars taken from the structure, given above in point 4.

4) The calculations took into account the real spacing of reinforcing bars measured in the revision holes.

From calculations made for non-corroded reinforcement and real material parameters in areas without corrosion, it appears that the load capacity in the analyzed horizontal crosssections ranges from 2.1 to $167.3 \%$. However, in the majority of analyzed cross-sections it does not exceed $25 \%$. This means that corrosion losses at the level of more than $25 \%$ of the reinforcement area already threaten the safe operation of the silos. There were quite a lot of such places.

\section{Summary}

1) On the basis of macroscopic evaluation, numerous tests carried out by the author's team and static and strength analysis, it was found that the technical condition of most silos in the area of damaged concrete structure and advanced corrosion of reinforcing steel is bad, and in areas of significant losses of structural reinforcement it is prefailure. 
2) Low quality of implementation of the object was found. Typical mistakes made during the construction of such objects are: too little reinforcement cover, excessive imperfections of silo walls, uneven distribution of reinforcing steel, insufficient anchoring lengths of reinforcement bars, non-homogeneous concrete at the height of silo walls, lack of proper joining of concrete in technological breaks, segregation of concrete mixture components.

3) An important cause of the current technical condition of the silos battery was also their more than fifty years of exploitation without any necessary repairs and protection of the external wall surface and all security elements.

4) The process of the silos degradation was significantly accelerated by many years without maintenance and repairs of the silos and lack of care for the technical condition of the object when they were in possession of previous owners.

5) Nevertheless, no obvious symptoms of exceeding the ultimate and serviceability limit states were observed. These could be: vertical cracks of excessive width or significant deformations of the silo walls.

6) Lack of clear signs of exhaustion of the load-bearing capacity of reinforced concrete silo walls results from hidden and large reserve capacities, as well as from the fact that more than $50 \%$ of the silo wall surface still has a load capacity greater than the one designed.

The walls of silos do not need strenghtening, but they need supplementation of the corroded reinforcing bars to the level ensuring their initial capacity. They also require concrete repair and restoration in the areas of its deterioration. Silos still can be safely operated according to their purpose, provided that the external walls are completely renovated and other repair works recommended below are carried out. Until the completion of the comprehensive renovation of the subject seventeen external silos, their operational capacity should be limited to $60 \%$ of the nominal capacity.

\section{Recommended range of repair}

Stage I - before the renovation of the external walls of the silos, the roof covering of the transport gallery and silos should be renovated, gutters and downpipes should be replaced, the expansion joints should be sealed and any leakages of rainwater should be removed.

Stage II - repairs of silos walls, supporting structure and discharge funnels consisting of:

1) Thorough removal of corroded concrete and unveiling of reinforcing bars to the place where corrosion free appears on the length of $\sim 1 \mathrm{~cm}$.

2) Cleaning the entire surface of the outer silo shells with a high pressure water jet (400 at).

3) Completing reinforcing defects by welding reinforcing bars to the existing in a corrosion-free area.

4) Implementation of bonding layer along with passivation of reinforcement (in one operation) or priming of substrate (depending on chosen renovation technology - Sika or KeraKoll).

5) Supplementing concrete losses with repair mortar of the selected system. Due to the depth of the cavities, choose a repair mortar that allows filling in one operation cavities with a depth of up to $40 \mathrm{~mm}$. With cavities reaching up to a maximum of $70 \mathrm{~mm}$ (predominantly up to $40 \mathrm{~mm}$ ), it will allow to replace cavities in one or maximum of two operations.

6) Filling the entire surface from the outside with a concrete trowel. 
7) Surface protection from the outside of silo walls with elastic paint that protects the concrete against adverse weather conditions after the ground has been primed.

Estimated size of renovation works of external walls of silos:

- total surface of external walls of silos $-3650 \mathrm{~m}^{2}$,

- repair area of defects up to $40 \mathrm{~mm}$ deep - around $550 \mathrm{~m}^{2}$,

- repair area of defects up to $75 \mathrm{~mm}$ deep - approximately $350 \mathrm{~m}^{2}$,

- weight of reinforcing steel to be restocked - about $3000 \mathrm{~kg}$ (steel EPSTAL B500SP).

View of silos during renovation shown in Figures 16 and 17

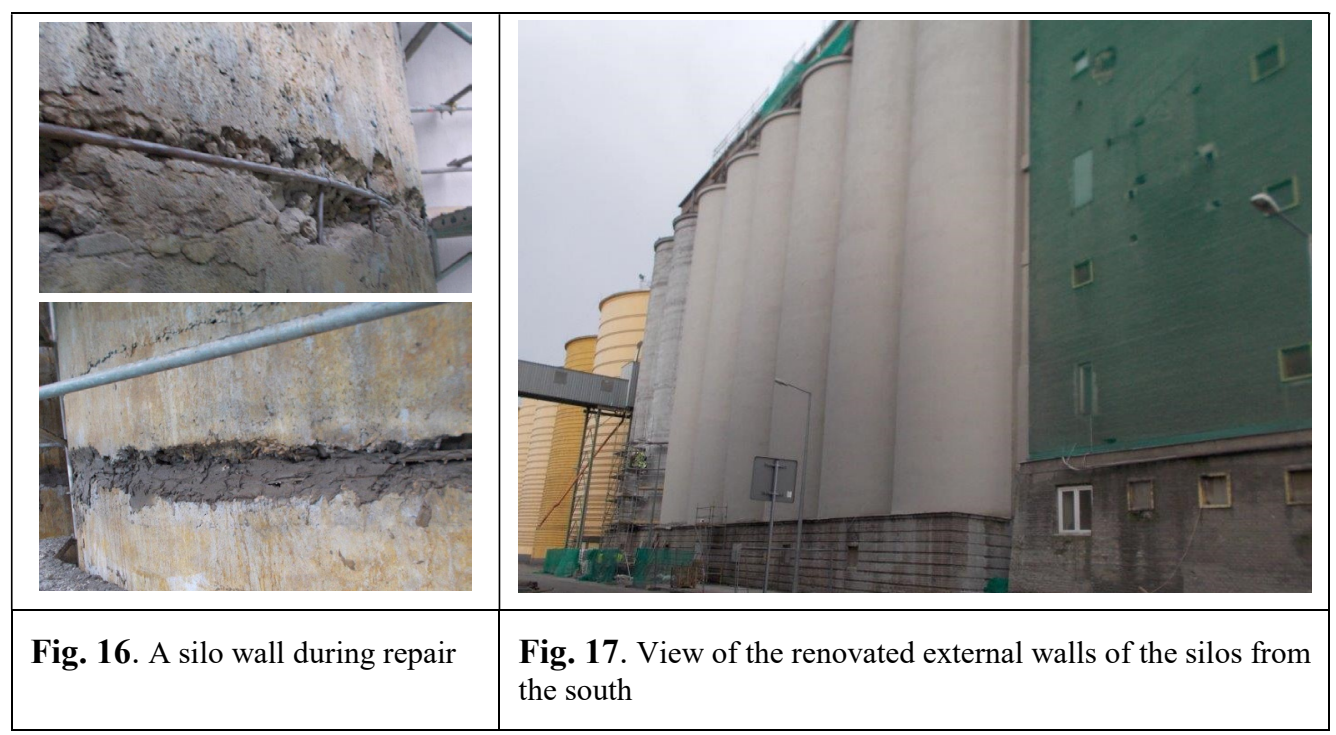

Stage III - other works:

1) Renovation of roofing in the $+2.90 \mathrm{~m}$ level.

2) Execution of ventilation chimneys with a minimum height of $2.0 \mathrm{~m}$ above the roofing at $+2,90 \mathrm{~m}$.

3) Renovation of external masonry walls.

4) Making vertical and horizontal damp-proof insulation of underground part of the object.

\section{References}

1. M. Kamiński, J. Mrozowicz, M. Maj, B. Podolski, R. Wróblewski, K. Gawron, Emergency condition of the blocked silos battery for oilseeds, XIX Scientific and Technical Conference "Awarie Budowlane" (Construction failures), Szczecin Międzyzdroje 1999, p. 821-828.

2. M. Kamiński, J. Mrozowicz, M. Maj, B. Podolski, R. Wróblewski, K. Gawron, Safety hazards of the blocked precast silos battery for rapeseed during the exploitation, XX Scientific and Technical Conference "Awarie Budowlane" (Construction failures), Szczecin - Międzyzdroje 2001, p. 183-191.

3. M. Kamiński, M. Maj, C. Bywalski, Use problems of reinforced concrete silos for grain after a several dozen years of exploitation, Przegląd Budowlany (Builders Review) 4, p. 157-160 (2012). 
4. W. Kubiszyn, K. Wróbel, M. Ostrowski, Assessment of the technical condition of the silo battery together with the renovation project at Oil Factory in Bodaczów, WIK K. Wróbel i W. Kubiszyn, Rzeszów (2017)

5. PN-EN 12504-2:2013. Testing concrete in structures - Part 2: Non-destructive testing - Determination of rebound number.

6. PN-EN 13791:2008. Assessment of in-situ compressive strength in structures and precast concrete components.

7. PN-EN 1542: 2000. Products and systems for the protection and repair of concrete structures - Test methods - Measurement of bond strength by pull-off.

8. PN-EN 14630: 2007. Products and systems for the protection and repair of concrete structures - Test methods - Determination of carbonation depth in hardened concrete by the phenolphthalein method.

9. Technical specifications (requirements) for the performance and acceptance of construction works. Volume I. General construction. Part 2. Arkady, Edition 4. Warsaw (1990).

10. PN-EN 1991-4:2008. Eurocode 1. Actions on structures. Part 4: Silos and tanks.

11. PN-EN 1992-1-1:2008. Eurocode 2. Designing of concrete structures. Part 1-1: General rules and rules for buildings.

12. PN-EN 1992-3:2008. Eurocode 2. Designing of concrete structures. Part 3: Silos and tanks for liquids. 